Turner, E. M. (1957). J. gen. Microbiol. 16, 531-533

\title{
The Effect of some Amino Acids on the Growth of Two Varieties of Ophiobolus graminis
}

\author{
By ELIZABETH M. TURNER* \\ Department of Botany, University of Oxford
}

\begin{abstract}
SUMMARY : An examination was made of the effect of certain amino acids on the growth of three isolates of Ophiobolus graminis Sacc. and of six isolates of $O$. graminis var. avenae, either as sole sources of nitrogen, or as supplements to ammonium nitrate. In all cases growth with aspartic acid was equal or nearly equal to that obtained with hydrolysed casein. Lysine and threonine were strongly inhibitory. The two varieties differ from each other in their reaction to cystine and cysteine, $O$. graminis itself making as good growth with these amino acids as with hydrolysed casein, and var. avenae being inhibited in growth.
\end{abstract}

Ophiobolus graminis Sacc. var. avenae differs from $O$. graminis itself in pathogenicity, being capable of causing a root rot (take-all) in oats as well as in wheat, in ascospore length, and in its capacity to make good growth in expressed sap from oat roots which does not support growth of $O$. graminis. The two varieties resemble each other closely in general morphology, in the type of infection and development of the disease in wheat, and in sensitivity to an inhibitor of growth and respiration obtained from oat sap (Turner, 1956). An investigation into the effect of amino acids on growth of the two varieties has been made. Here also, while resembling each other in certain well-marked reactions, in particular in intolerance of lysine and threonine, the two varieties can be distinguished from each other in their response to the sulphur-containing amino acids cystine and cysteine.

\section{METHODS}

Fungal isolates. The isolates previously described (Turner, 1956) were used. They are designated as $\mathrm{W}$ or $\mathrm{O}$ according to spore length, $\mathrm{W}$ isolates belonging to Ophiobolus graminis, $\mathrm{O}$ isolates to $O$. graminis var. avenae. All $\mathrm{W}$ isolates grew well in a defined medium, as did isolates $\mathrm{O} 1, \mathrm{O}_{2}, \mathrm{O3}$, and $\mathrm{O} 4$. The remaining $\mathrm{O}$ isolates grew poorly. All were mycelial isolates from infected roots of wheat or oats.

Measurement of growth. The isolates were grown in a defined medium of the following composition per $1 .: 1.0 \mathrm{~g}$. $\mathrm{KH}_{2} \mathrm{PO} ; 2 \cdot 0 \mathrm{~g} . \mathrm{MgSO}_{4} \cdot 7 \mathrm{H}_{2} \mathrm{O} ; 3.0 \mathrm{~g}$. $\left.\mathrm{Na}_{2} \mathrm{HPO}_{4}\right) ; 20 \cdot 0$ g. glucose; $1 \mathrm{mg}$. biotin; $1 \mathrm{mg}$. thiamine. This will be referred to as basal medium. To this was generally added $5 \cdot 0 \mathrm{~g}$. ammonium nitrate/l., the medium then being called 'AN basal'. Additions of hydrolysed casein or amino acids were made as described. These gave the same results whether autoclaved $\left(120^{\circ}\right.$ for $10 \mathrm{~min}$.) or sterilized by filtration through sintered glass

* Present address: Division of Biology, California Institute of Technology, Pasadena, California, U.S.A. 
and were therefore added before autoclaving. Glucose was autoclaved separately and added aseptically to the flasks. Flasks of $100 \mathrm{ml}$. capacity were used, each containing $5 \mathrm{ml}$. medium; four replicates were set up for each treatment. Each flask was inoculated with one disk $3 \mathrm{~mm}$. in diam. cut with a drawn-out glass tube from the growing edge of mycelial mats on $2 \%$ malt agar. The flasks were incubated at $25^{\circ}$ for $5 \frac{1}{2}$ days and the mats were then dried, washed and weighed. A control was run for each experiment with AN basal medium alone; the results are generally expressed relative to growth on this medium. In most cases each figure represents the average result of three separate experiments.

\section{RESULTS}

Survey of amino acid effects. The addition of $0.05 \%(\mathrm{w} / \mathrm{v})$ hydrolysed casein (Oxoid) to the AN basal medium increased growth of Ophiobolus graminis isolate $W_{1}$ by about $40 \%$ over the control. In the absence of an inorganic nitrogen source a mixture of 19 amino acids and asparagine and glutamine, each at a final concentration of $0.0025 \mathrm{M}$ (giving a total addition by weight of $0.55 \%(\mathrm{w} / \mathrm{v}))$ when compared with $0.55 \%(\mathrm{w} / \mathrm{v})$ hydrolysed casein gave equal growth.

Table 1. Effects on growth of isolates of $O$ phiobolus graminis $(W)$ and $O$. graminis var. avenae $(O)$ of amino acids added singly (0.004 $\mathrm{M})$ to $A N$ basal medium

For precise definition of classes see text. Isolates $\mathrm{O}_{2}, \mathrm{O}_{5}$, and $\mathrm{O}_{6}$ tested only with aspartic acid, glycine, threonine, lysine, methionine, cystine and cysteine.

A. Good for all isolates (classes 1 or 2):

L-Asparagine, L-aspartic acid

B. Good to ineffective for all isolates (classes 1, 2 or 3): L-Glutamine, L-glutamic acid, L-proline, DL-valine

C. Ineffective or poor for all isolates (classes 3 or 4): L-Leucine, DL-isoleucine, DL-phenylalanine

D. Poor or bad for all isolates (classes 4 or 5): DL-Threonine, L-lysine, DL-methionine

E. Good for $W$ isolates, poor or bad for $O$ isolates:

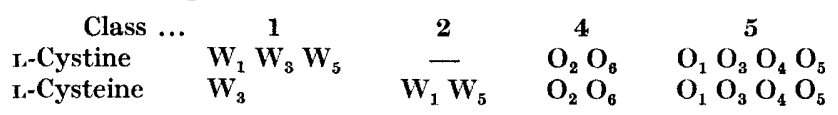

F. Effects variable:

\begin{tabular}{lcllll}
\multicolumn{1}{r}{ Class $\ldots$} & 1 & \multicolumn{1}{c}{2} & \multicolumn{1}{c}{3} & \multicolumn{1}{c}{4} & 5 \\
Glycine & - & $\mathrm{W}_{1} \mathrm{~W}_{3} \mathrm{~W}_{5}$ & $\mathrm{O}_{4}$ & $\mathrm{O}_{1} \mathrm{O}_{2} \mathrm{O}_{3} \mathrm{O}_{8}$ & $\mathrm{O}_{5}$ \\
L-Alanine & $\mathrm{W}_{3}$ & $\mathrm{~W}_{1} \mathrm{~W}_{5}$ & $\mathrm{O}_{1} \mathrm{O}_{4} \mathrm{O}_{5}$ & $\mathrm{O}_{3}$ & - \\
L-Serine & - & $\mathrm{W}_{3}$ & $\mathrm{~W}_{1} \mathrm{~W}_{5}$ & $\mathrm{O}_{1} \mathrm{O}_{3} \mathrm{O}_{4}$ & - \\
L-Histidine & - & $\mathrm{W}_{5} \mathrm{O}_{3}$ & $\mathrm{~W}_{1} \mathrm{~W}_{3} \mathrm{O}_{4}$ & - & $\mathrm{O}_{1}$ \\
L-Arginine & - & $\mathrm{W}_{5} \mathrm{O}_{3}$ & $\mathrm{~W}_{1} \mathrm{~W}_{3} \mathrm{O}_{4}$ & - & - \\
L-Tryptophane & $\mathrm{W}_{5} \mathrm{O}_{3}$ & $\mathrm{~W}_{3}$ & $\mathrm{O}_{4}$ & $\mathrm{~W}_{1} \mathrm{O}_{1} \mathrm{O}_{2}$ & - \\
L-Tyrosine & $\mathrm{O}_{3}$ & $\mathrm{~W}_{5} \mathrm{O}_{4}$ & $\mathrm{~W}_{3}$ & $\mathrm{~W}_{1} \mathrm{O}_{1}$ & -
\end{tabular}

Individual amino acids as sole nitrogen source were added singly to $0.04 \mathrm{M}$ and tested with isolates $\mathrm{W}_{1}$ and $\mathrm{O}_{3}$; as supplements to the inorganic source they were added to $0.004 \mathrm{~m}$ (representing an addition of $0.053 \%$ for aspartic acid) and tested with six isolates, three of each variety; partial tests were made with three further isolates. 
Growth in the control medium differed considerably between different isolates, as did growth with $0.05 \%(\mathrm{w} / \mathrm{v})$ hydrolysed casein. Comparison between isolates was therefore most easily obtained by broadly grouping results into five classes, viz. (1) good, growth about equal to that with hydrolysed casein; (2) moderately good, growth intermediate between that with hydrolysed casein and that in the AN basal medium alone; (3) ineffective, growth the same as in the control; (4) poor, some decrease in growth compared to the control; and (5) bad, growth less than $50 \%$ of the control. Results given in Table 1 show (a) that asparagine and aspartic acid were as favourable to growth of all isolates as was hydrolysed casein, $(b)$ that lysine, threonine and methionine were inhibitory to growth of all isolates, $(c)$ that in general the $\mathbf{O}$ isolates were the more susceptible to growth inhibition by single amino acids, and $(d)$ that, in particular, all $O$ isolates were strongly inhibited, whereas the $W$ isolates were stimulated in growth by cystine and cysteine.

When amino acids were added singly as sole nitrogen source to $0.04 \mathrm{M}$ (only isolates $\mathrm{W}_{1}$ and $\mathrm{O}_{3}$ tested) the effects were similar except that leucine, isoleucine, valine, proline, tryptophane, tyrosine and phenylalanine were all poor nitrogen sources for both isolates (classes 4 or 5 ).

In their reactions to amino acids present singly in the medium the two varieties of Ophiobolus graminis do not differ much from the generalized scheme drawn up by Pelletier \& Keitt (1954) from reports by different investigators on a score of fungi from all taxonomic groups. The clear distinction between the two varieties in their reaction to cystine and cysteine (in Pelletier \& Keitt's grouping 'poor') are therefore of significance, at least indicating a difference in metabolism between them, and possibly being connected with their difference in pathogenicity.

\section{REFERENCES}

Preldetier, R. L. \& Keitr, G. W. (1954). Venturia inaequalis (Cke.) Wint. VI. Amino acids as sources of nitrogen. Amer. J. Bot. 41, 362 .

TUnNER, E. M. (1956). The nature of the resistance of oats to the take-all fungus. II. Inhibition of growth and respiration of Ophiobolus graminis Sacc. and other fungi by a constituent of oat sap. J. exp. Bot. 7, 80 .

(Received 6 September 1956) 